\title{
An approach to the dyeing of semi dull and cationic dye able polyester with disperse dye and comparison with cotton polyester blend dyeing process
}

\begin{abstract}
This paper puts forth the dominance of SD polyester over the cellulosic cotton fiber. SD polyester being capable of adopting the appearance of cotton fiber and cheaper than cotton fiber that's why cotton fiber is chosen for this paper. The fabric composition consists of $50 \%$ of SD polyester and $50 \%$ of $\mathrm{CD}$ able polyester fiber. The exhaust dyeing process is followed at high temperature. Both $\mathrm{SD}$ and $\mathrm{CD}$ polyester were dyed at the same time duration of 40 minutes and temperature were $135^{\circ} \mathrm{C}$ and $90^{\circ} \mathrm{C}$ respectively. For this purpose, experiments were done on $80 / 20$ cotton/polyester and $50 / 50 \mathrm{SD} / \mathrm{CD}$ polyester which shows the same results. The results were based on the parameters like GSM, fastness, stitch length and a same dying recipe. After completing the dying process the parameter like shrinkage tolerance (3-5) \%, shade matching $3 \%$, wash fastness at $60^{\circ} \mathrm{C}(4-5) \%$, wet rubbing fastness (4-5) \%, dry rubbing fastness (45 ) $\%$, spirality of fabric $3 \%$ (Max) were found. The only drawback of $50 / 50 \mathrm{SD}$ and $\mathrm{CD}$ polyester fabric is the coziness of the fabric as cotton fabric is better on this. When all the dyeing parameters and dying process is considered; SD and CD polyester shows better performance than cotton.
\end{abstract}

Keywords: semi dull polyester, cationic dye able polyester, cotton, disperse dye
Volume 5 Issue I - 2019

\author{
Haque AKMM,' Shibly MAH,' Hasan MM,' \\ Zerin I,' Hossain MT,' ${ }^{2}$ Mahir FI,' Nahiun \\ KM,' Sarker B' \\ 'Department of Textile Engineering, National Institute of Textile \\ Engineering \& Research, Bangladesh \\ ${ }^{2}$ Research Assisteant, Texas Tech University, USA
}

\begin{abstract}
Correspondence: Haque AKMM, Department of Textile Engineering, National Institute of Textile Engineering \& Research; Savar, Dhaka-1350, Bangladesh,

Email monjurulhaque0I@niter.edu.bd
\end{abstract}

Received: December 27, 2018| Published: February 05, 2019
Abbreviations: SD, semi-dull; POY, partially oriented yarn; $\mathrm{CD}$, cationic dye

\section{Introduction}

SD polyester is a Special type of fiber which is composed of phony methods. ${ }^{1}$ Researchers have studied for the replacement of the natural fiber, cotton with synthetic fiber, semi-dull polyester. SD polyester provides good spinning quality as well as good durability and strength. The most important feature of Semi dull polyester fiber is that it has the similar appearance of cotton fiber. ${ }^{2}$ Another three major features of SD polyester fiber as; good color fastness, optimum finish, smoke texture.

The origin of the SD polyester fiber is the POY which has lower luster in order to POY in case of bright yarns. ${ }^{2}$ The attempt of today's engineer is to replace the cotton fiber with polyester fiber for its some of the major lacking's like more moisture absorbency, shrinkage, wrinkling etc. In addition, the SD is the filament yarn of the polyester fiber. Consequently, this SD polyester fiber has the variation of counts in denier and micro denier. ${ }^{3,4}$

Cotton fiber is the most widely used and 7000 thousand years old fiber to be proved. ${ }^{5,6}$ Chemically cotton fibers are mostly made of alpha-cellulose $(88.00 \%-96.5 \%)$ where nano cellulose is positioned or either cuticle and primary wall or inside the lumen of the fibers whereas the secondary cell wall is pure cellulose. Cotton is the purest of cellulose and ample in nature. ${ }^{6,7}$ When examined in the chemical composition varies with the variation of its origin and other factors. However, the Nano-cellulose include proteins $(1 \%$ $1.9 \%)$, waxes $(0.4 \%-1.2 \%)$, pectin ( $1 \%-2 \%)$, inorganic $(0.7 \%-1.6 \%)$, others $(0.5 \%-0.8 \%){ }^{8}$ The crystalline region dominates the cellulosic cotton fiber and alpha cellulose is prominent in its long and rigid molecular structure., ${ }^{9} 10$ The amorphous region cellulosic cotton leads to the access of heat or any other reaction. Cotton is popular for its availability, ready reaction with dyes and chemicals. ${ }^{10}$ Cotton fiber needs special different finishes to retain the different effects on it. ${ }^{11}$ The objectives of this research are to completely replace cotton fiber for its undeniable demerit with SD and CD polyester fiber with a view to reducing the expense of dyeing. ${ }^{12}$

\section{Material and methods}

In general, disperse dye is mostly used for polyester fiber and it is a hydrophobic fiber. Disperse dyes are the derivatives of azo, anthraquinone, nitro, and quinone group. ${ }^{13,14}$ Such as:

$$
\text { Dye- } \mathrm{NH}-\mathrm{CH}_{2}-\mathrm{SO}_{3} \mathrm{Na}+\mathrm{H}_{2} \mathrm{O} \quad \mathrm{NH}_{2} \text { Dye }+\mathrm{CH}_{2} \mathrm{O}+\mathrm{NaHSO}_{4}
$$

Dyes like; Dispersol Fast Yellow G, Fast Orange G, Violet 2R, Blue GN etc. these dyes do not require carrier for swelling and keeps dyeing at boiling temperature.

\section{Fabric preparation}

The process has been done in two types of polyester fabric, i.e. SD polyester and CD polyester. In both cases, disperse dyes were used.

\section{Semi dull polyester}

Around $10 \mathrm{~kg}$ single jersey mesh fabric was taken. The fabric was collected from Masco Industries Limited, Dhaka, Bangladesh. GSM of the fabric was 165. Dye liquor was about 100 liters. The recipe followed for the dyeing as follows: 


\begin{tabular}{|l|l|}
\hline RI & $2 \%$ \\
\hline AB45 & $1 \%$ \\
\hline DFM & $2 \%$ \\
\hline Terasil Blue WBLS & $1 \%$ \\
\hline Terasil Red WW 3BS & $0.03 \%$ \\
\hline Teracil Yellow W6GS & $0.003 \%$ \\
\hline Caustic soda & $2.00 \mathrm{~g} / 1$ \\
\hline Hydrose BASF & $3 \mathrm{~g} / 1$ \\
\hline Acetic acid & $1 \mathrm{~g} / 1$ \\
\hline
\end{tabular}

Initially, a paste of dye and dispersing agent is prepared and water is added to it. The $\mathrm{pH}$ was controlled by acetic acid. Materials and other dye auxiliaries were added at $45^{\circ} \mathrm{C}$. This condition was kept for 15 minutes. Then the dye bath temperature was raised to $130^{\circ} \mathrm{C}$ and kept the condition for one hour. ${ }^{15}$ The dye was diffused in the dye bath and adsorbed by the fabric and thus required shade was obtained. During the dyeing $\mathrm{pH}$ was kept between 4-4.5. After that the dye bath was cooled down as early as possible. ${ }^{15}$ The fabric was rinsed and reduction cleaning was done.

\section{Result and discussion}

\section{Physical test report}

In this research, only physical test has been carried out. The test results are given below Table 1 .

A comparative study was made between cotton fiber and polyester fiber; keeping the GSM, color, machine detail, style same (Table 2).

It was observed that the polyester fiber showed higher results as cotton fiber when the dyeing parameters were kept same for both the fibers. Analytical details of cotton and polyester fibers are given below Table 3 .

Table I Physical test results

\begin{tabular}{|c|c|c|c|c|c|}
\hline Test name & & Before wash & After wash & Test found \% & Tolerance \% \\
\hline Dimensional stability to wash & Length & $35.00 \mathrm{~mm}$ & $34.09 \mathrm{~mm}$ & $-2.60 \%$ & $\pm 5.00 \%$ \\
\hline (BS EN ISO 6330:2001) & Width & $35.00 \mathrm{~mm}$ & $34.72 \mathrm{~mm}$ & $-0.80 \%$ & $\pm 5.00 \%$ \\
\hline Spirality & & & & $0.00 \%$ & $\pm 5.00 \%$ \\
\hline GSM & & & & 165 & 165 \\
\hline Fabric Width & & & & $48^{\prime \prime}$ & $48^{\prime \prime}$ \\
\hline
\end{tabular}

Table 2 A comparative studies was made between cotton fiber and polyester fiber

\begin{tabular}{|c|c|c|c|c|c|c|c|c|c|}
\hline \multirow{2}{*}{ Fabrication } & \multirow{2}{*}{$\begin{array}{l}\text { Stitch } \\
\text { length }\end{array}$} & \multirow{2}{*}{ GG } & \multirow{2}{*}{ Fabric dia } & \multirow{2}{*}{ Color } & \multirow{2}{*}{ Qty. } & \multicolumn{3}{|c|}{ Additional instruct } & \multirow{2}{*}{ Remark } \\
\hline & & & & & & HT ST & Dry & Comp & \\
\hline $\begin{array}{l}80 \% \text { Cotton } \\
\text { and } 20 \% \text { Spun } \\
\text { Polyester, } 28 / 1 \mathrm{Ne} \text {, } \\
\text { Mesh Single } \\
\text { Jersey, GSM-165 }\end{array}$ & $2.65 \mathrm{~mm}$ & 24 & $\mathrm{NON} / 35$ & $\begin{array}{l}\text { Cotton Part Dye-15- } \\
0543 \text { TCX }\end{array}$ & $10 \mathrm{~kg}$ & N/A & As set & As set & $\begin{array}{l}\text { Follow the design } \\
\text { file }\end{array}$ \\
\hline $\begin{array}{l}100 \% \text { Filament } \\
\text { Polyester( } 50 \% \text { CD } \\
\text { and } 50 \% \text { SD), } 28 / 1 \\
\text { Ne, GSM- } 165\end{array}$ & $2.65 \mathrm{~mm}$ & 24 & NON/35 & $\begin{array}{l}\text { New Technology in } \\
\text { Dyeing only CD Part } \\
\text { Dye-19-4053 TCX + }\end{array}$ & $10 \mathrm{~kg}$ & N/A & As set & As set & $\begin{array}{l}\text { Follow the design } \\
\text { file (Cationic }+ \\
\text { Anionic Dyeing } \\
\text { Method) }\end{array}$ \\
\hline
\end{tabular}

Table 3 Analytical details of cotton and polyester fibers

\begin{tabular}{lll}
\hline Test parameter & $\mathbf{8 0 \%}$ Cotton and 20\% Polyester & $\begin{array}{l}\mathbf{1 0 0 \%} \text { Filament polyester (50\% } \\
\text { CD and 50\% SD) }\end{array}$ \\
\hline Wash Fastness at $60^{\circ} \mathrm{C}$ & $3-4$ & $4-5$ \\
Wet Rubbing fastness & $3-4$ & $4-5$ \\
Dry Rubbing Fastness & $3-4$ & $4-5$ \\
Spirality of Fabric & $5 \%$ & $3 \%$ \\
Pilling of Fabric & $3-4$ & $4-5$ \\
\hline
\end{tabular}

\section{Conclusion}

Dyeing of cotton and polyester fiber with disperse dyes has been characterized in this investigation. A comparative study of cotton and polyester fiber shows that polyester fiber requires similar time to cotton and similar fastness properties. Semi dull polyester fiber is comparatively cheaper than cotton fiber and its appearance is similar to cotton fiber. Cotton fiber for its inherited demerits like yellowness, more moisture absorbency can successfully be replaced by SD polyester fiber. 


\section{Acknowledgments}

None.

\section{Conflicts of interest}

Authors declare that there is no conflicts of interest.

\section{References}

1. McCartney PD, Voshell SW. Warp-knitted textile fabric shoe liner and method of producing same. Google Patents; 1995.

2. Evans R, Wallis AF. Cellulose molecular weights determined by viscometry. Journal of applied polymer science. 1989;37(8):23312340.

3. Vandevivere PC, Bianchi R, Verstraete W. Treatment and reuse of wastewater from the textile wet-processing industry: Review of emerging technologies. Journal of Chemical Technology \& Biotechnology. 1998;72(4):289-302.

4. Ferrero F. Wettability measurements on plasma treated synthetic fabrics by capillary rise method. Polymer testing. 2003;22(5):571-578.

5. Mwaikambo LY, Ansell MP. Chemical modification of hemp, sisal, jute, and kapok fibers by alkalization. Journal of applied polymer science. 2002;84(12):2222-2234

6. Nishiyama Y, Langan P, Chanzy H. Crystal structure and hydrogenbonding system in cellulose I $\beta$ from synchrotron X-ray and neutron fiber diffraction. Journal of the American Chemical Society. 2002;124(31):9074-9082.
7. Langan P, Nishiyama Y, Chanzy H. A revised structure and hydrogenbonding system in cellulose II from a neutron fiber diffraction analysis. Journal of the American Chemical Society. 1999;121(43):9940-9946.

8. Morán JI, Alvarez VA, Cyras VP, et al. Extraction of cellulose and preparation of nanocellulose from sisal fibers. Cellulose. 2008;15(1):149-159.

9. Heinze T, Liebert T, Koschella A. Esterification of polysaccharides. Springer Science \& Business Media; 2006.

10. Kang EJ, Lee E. Total synthesis of oxacyclic macrodiolide natural products. Chemical reviews. 2005;105(12):4348-4378.

11. Lam Y-L, Kan C-W, Yuen C-WM, Developments in functional finishing of cotton fibres-wrinkle-resistant, flame-retardant and antimicrobial treatments. Textile Progress. 2012;44(3-4):175-249.

12. Kelly KD. Imaged nonwoven fire-retardant fiber blends and process for making same. Google Patents; 2004.

13. Chequer FMD, Rodrigues de Oliveira GA, Anastácio Ferraz ER, et al. Textile dyes: dyeing process and environmental impact, in Eco-friendly textile dyeing and finishing. 2013.

14. Ujhelyiova A, Bolhova E, Oravkinova J, et al. Kinetics of dyeing process of blend polypropylene/polyester fibres with disperses dye. Dyes and Pigments. 2007;72(2):212-216.

15. Cegarra J, Puente P. Considerations on the kinetics of the dyeing process of polyester fibers with dispersed dyes. Textile Research Journal. 1967;37(5):343-350. 